\title{
BUBBLE LIFT-OFF IN FORCED CONVECTIVE SUBCOOLED BOILING FLOW
}

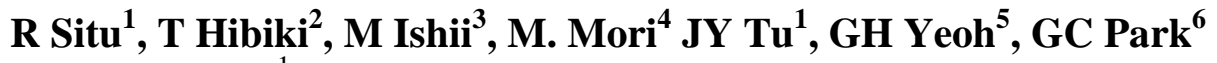 \\ ${ }^{1}$ RMIT University, Bundoora, Australia \\ ${ }^{2}$ Kyoto University, Kumatori, Japan \\ ${ }^{3}$ Purdue University, West Lafayette, USA \\ ${ }^{4}$ Tokyo Electric Power Company, Tsurumi, Japan \\ ${ }^{5}$ Australian Nuclear Science and Technology, Sydney, Australia \\ ${ }^{6}$ Seoul National University, Seoul, Korea
}

\begin{abstract}
Bubble lift-off is different from bubble departure, and it is more suitable for the boundary condition for numerical simulation of subcooled boiling flow. A force balance analysis of a growing bubble was performed to predict the bubble lift-off size. The dimensionless form of the bubble lift-off diameter was formulated to be a function of Jacob number and Prandtl number. The modeling of bubble lift-off frequency requires careful study of bubble collapse during sliding. Forced convective subcooled boiling flow experiments were conducted in a BWR-scaled vertical upward annular channel. Water was used as the testing fluid, and the tests were performed at atmospheric pressure. A high-speed digital video camera was applied to capture the dynamics of the bubble nucleation process. Bubble lift-off diameters and lift-off frequencies were obtained from the images for a total of 92 test conditions. The bubble lift-off frequency was found to be same as the bubble departure frequency. The proposed bubble lift-off diameter model agreed well with the experimental data within the averaged relative deviation of $\pm 33.6 \%$.
\end{abstract}

\section{Nomenclature}

$\begin{array}{ll}b & \text { constant } \\ C^{+} & \text {constant } \\ C_{f} & \text { friction coefficient } \\ C_{l} & \text { shear lift coefficient } \\ C_{r} & \text { relative velocity coefficient } \\ C_{p} & \text { specific heat at constant pressure } \\ D_{H} & \text { hydraulic equivalent diameter } \\ D_{l o} & \text { bubble lift-off diameter } \\ D_{l o}^{*} & \text { dimensionless bubble lift-off diameter } \\ D_{w} & \text { bubble contact diameter on surface } \\ E & \text { averaged prediction error } \\ F & \text { enhance factor on } h_{c} \text { due to the presence } \\ & \text { of vapor } \\ F_{g} & \text { growth force } \\ F_{s} & \text { surface tension force } \\ F_{s l} & \text { shear lift force } \\ G & \text { mass flux } \\ G_{s} & \text { dimensionless fluid velocity gradient } \\ H & \text { bubble height } \\ h & \text { heat transfer coefficient } \\ i_{f g} & \text { heat of vaporization (latent heat) } \\ \mathrm{Ja} & \text { Jacob number }\end{array}$

$k \quad$ thermal conductivity

$k^{+} \quad$ constant

$n$ constant

Pr Prandtl number

$q^{\prime \prime} \quad$ heat flux

$\mathrm{Re}_{b}$ bubble Reynolds number

$\mathrm{Re}_{T P}$ two-phase flow Reynolds number

$r_{b} \quad$ bubble radius

$\dot{r}_{b} \quad$ first derivative of bubble radius with respect to time

$\ddot{r}_{b} \quad$ second derivative of bubble radius with respect to time

$S \quad$ suppression factor

$T$ temperature

$t$ time

$t_{l o} \quad$ time of bubble lift-off

$V_{b}$ bubble volume

$V_{f} \quad$ volume of virtual added mass

$v_{b x}$ bubble front velocity on $x$-direction

$v_{f}(x)$ liquid velocity profile near wall

$\bar{v}_{f} \quad$ area-averaged liquid velocity 


$\begin{array}{ll}v_{g} & \begin{array}{l}\text { gas velocity } \\ v_{r}\end{array} \\ & \begin{array}{l}\text { relative velocity between bubble center } \\ \text { of mass and the liquid phase }\end{array} \\ z & \text { coordinate } \\ & \text { axial coordinate }\end{array}$

$\begin{array}{ll}d & \text { departure } \\ e & \text { effective } \\ f & \text { liquid phase } \\ f i n & \text { liquid at inlet } \\ g & \text { vapor phase } \\ h & \text { hydraulic } \\ i & \text { interfacial } \\ i n & \text { inlet } \\ l o & \text { bubble lift-off } \\ N B & \text { nucleate boiling } \\ \text { sat } & \text { saturation } \\ w & \text { wall } \\ x & x \text {-direction } \\ y & y \text {-direction }\end{array}$

$$
\begin{array}{lr}
\text { Superscripts } \\
* \quad \text { dimensionless quantities } \\
+\quad \text { dimensionless quantities }
\end{array}
$$

\section{Introduction}

For boiling water reactor (BWR) safety, the capability to predict two-phase flow behaviours in forced convective subcooled boiling flow is of crucial importance. Currently, the two-fluid model (1975) can potentially offer an advanced and accurate analysis of thermal-hydraulic characteristics for nuclear reactor systems. However, the interfacial transfer terms in the model are extreme difficult to model because of the discontinuity induced by the presence of interfaces separating the phases. The interfacial area transport equation (1995) was proposed to model various heat and mass transport mechanism across the interface. Furthermore, to apply the interfacial area transport equation to subcooled boiling conditions, several parameters such as nucleation number density, bubble lift-off size and bubble lift-off frequency are required as the boundary conditions.

The concept of bubble lift-off, i.e., bubble detaching from the heater surface, is different from that of bubble departure, i.e. bubbles detaching from the nucleation site. The bubble departure phenomena have been investigated since 1950s. However, bubble lift-off has not been paid attention to until 1990s. Klausner et al. (1993) and Zeng et al. (1993) carried out force balance analysis on a bubble in saturated horizontal forced convection boiling. They found out that several forces, such as surface tension, hydrodynamic pressure force, and contact pressure force, could be neglected at the moment of bubble lift-off, because the bubble contact area on the wall was approximated to be zero. Hence, the bubble lift-off diameter was calculated based on the simplified force balance equation.

Literature review shows that bubble departure size at forced convection boiling have been studied extensively (Situ et al.2006). However, only a few studies were conducted on the bubble lift-off size in convective boiling, which is more crucial to the interfacial area transport equations. When bubble is attaching to the heater surface, they are heated up from the heating surface through a micro-layer under the bubbles. The heat transfer mechanisms at the wall are quite different from those in the bulk region. However, only the heat transfer mechanisms in the bulk region are adopted in the interfacial area transport equation to govern bubble growth or condensation. Hence, bubble departure diameter is not proper to act as the boundary condition for the interfacial area transport equation. 
Similarly, Bubble Lift-off frequency, another important boundary condition parameter, has not been addressed in literature yet. In contrast, bubble departure frequency has been studied mainly in pool boiling. Bubble departure frequency in flow boiling has been modelled mainly by correlations. Until 1997, Podowski et al. (1997) proposed a mechanistic model of bubble departure frequency in forced convective boiling flow.

The purpose of this research is to experimentally and theoretically study the bubble lift-off size and bubble lift-off frequency in vertical upward forced-convective subcooling boiling flow. The investigation will focus more on bubble lift-off size, because bubble lift-off frequency is most equal to the bubble departure frequency by experimental findings in the present study.

\section{Modelling of Bubble Lift-Off Diameter}

\subsection{Balance of forces acting on bubble at lift-off}

The force balance at the moment of bubble departure is described in the previous paper (Situ et al. 2006), and will not be detailed here. Furthermore, the force balance in $x$-direction at the moment of the bubble lift-off is shown in Figure 1 . The bubble surface tension force, $F_{s}$, is neglected because the bubble contact area on the heater surface becomes zero at the moment of lift-off. Thus, only shear lift force, $F_{s l}$, and growth force, $F_{d u}$, control the bubble in x-direction, ad the growth force is normal to flow direction:

$$
F_{g}+F_{s l}=0 \text {. }
$$

\subsubsection{Growth force}

Chen et al. (2003) provided the virtual added mass for a spherical bubble attached to a wall as

$$
V_{f}=\frac{11}{12} \pi r_{b}^{3},
$$

where $r_{b}$ is bubble radius. Hence, the inertial force of the added mass becomes growth force

$$
F_{g}=\frac{d\left(\rho_{f} V_{f} u_{b x}\right)}{d t}=\rho_{f}\left(V_{f} \frac{d^{2} H}{d t^{2}}+\frac{d H}{d t} \frac{d V_{f}}{d t}\right),
$$

where $H$ is the bubble height measured from the wall, and $u_{b x}$ is the bubble front velocity on $x$ direction $u_{b x}=d H / d t$. In the case of spherical bubble, $H$ is equal to the bubble diameter. Thus the growth force can be obtained from Equations (2) and (3),

$$
F_{g}=-\rho_{f} \pi r_{b}^{2}\left(\frac{11}{2} \dot{r}_{b}^{2}+\frac{11}{6} r_{b} \ddot{r}_{b}\right)
$$

where $\dot{r}_{b}$ is the derivative of the bubble radius with respect to time, and $\ddot{r}_{b}$ is the second derivative of the bubble radius with respect to time.

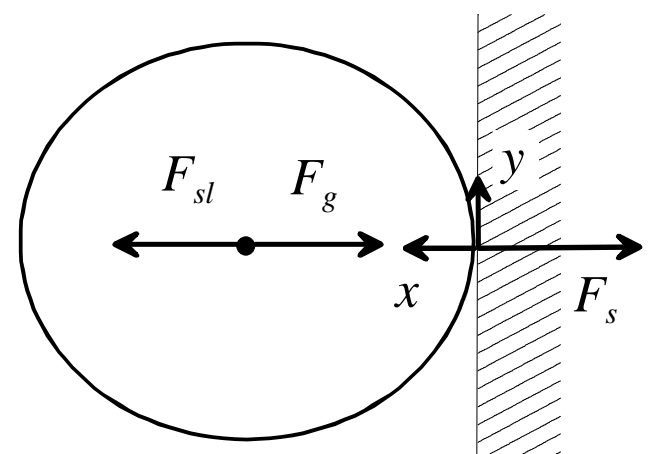

Figure 1. Force balance of a vapor bubble at lift-off. 
The bubble growth has been correlated with Jacob number by Zuber (1961) in his popular equation

$$
r_{b}=\frac{2 b}{\sqrt{\pi}} \mathrm{Ja} \sqrt{\alpha_{f} t}
$$

where $b$ is a coefficient modified as 1.73 by Zeng et al. (1993) by comparing with various pool boiling data, and the definition of the Jacob number is

$$
\mathrm{Ja}=\frac{\rho_{f} C_{p f} \Delta T_{s a t}}{\rho_{g} i_{f g}}=\frac{\rho_{f} C_{p f}\left(T_{w}-T_{s a t}\right)}{\rho_{g} i_{f g}},
$$

The wall superheat is used as the superheat in the Jacob number for pool boiling or saturated boiling. However, for subcooled boiling flow, the wall superheat is suppressed due to the flow of subcooled bulk liquid. An effective Jacob number was proposed (Kocamustafaogullari and Ishii 1983) to take account of the hydraulic effect.

$$
\mathrm{Ja}_{e}=\frac{\rho_{f} C_{p f} \Delta T_{e}}{\rho_{g} i_{f g}},
$$

Where the effective superheat is

$$
\Delta T_{e}=S\left(T_{w}-T_{s a t}\right)
$$

where $S$ is the suppression factor

$$
S=\frac{1}{1+2.53 \times 10^{-6} \operatorname{Re}_{T P}^{1.17}},
$$

where $\operatorname{Re}_{T P}$ is the two-phase Reynolds number.

\subsubsection{Shear lift force}

Saffman (1965) derived the shear lift force on a solid sphere at zero Reynolds number. McLaughlin (1991) extended Saffman's work to arbitrary shear rate by retaining the additional convective term that arises from the shear. For high Reynolds number, Auton (1987) derived an expression for the shear lift force on a sphere in an inviscid shear flow. Mei and Klausner (1994) modified McLaughlin's model to suit for a bubble, and interpolated with Auton's equation to derive an expression for shear lift force over wide range of Reynolds number as

$$
F_{s l}=\frac{1}{2} C_{l} \rho_{f} \pi r_{b}^{2} v_{r}^{2},
$$

where $v_{r}$ is the relative velocity between the bubble centre of mass and the liquid phase, i.e., $v_{r}=v_{f}$ $-v_{g}$, and the $C_{l}$ is the shear lift coefficient given by

$$
C_{l}=3.877 G_{s}^{1 / 2}\left(\operatorname{Re}_{b}^{-2}+0.014 G_{s}^{2}\right)^{1 / 4},
$$

Where the dimensionless shear rate of the liquid flow

$$
G_{s}=\left|\frac{d v_{f}}{d x}\right| \frac{r_{b}}{v_{r}},
$$

and $\operatorname{Re}_{b}$ is the bubble Reynolds number

$$
\mathrm{Re}_{b}=\frac{2 r_{b} v_{r}}{v_{f}} .
$$

In Equation (13), Mei and Klausner (1994) maintained that the ratio of the lift forces on a spherical inviscid bubble and a solid sphere is 2/3. However, Legendre and Magnaudet (1997) corrected this ratio to be $(2 / 3)^{2}$, i.e., 0.444 . Thus, Equation (13) is modified with this corrected ratio

$$
C_{l}=2.585 G_{s}^{1 / 2}\left(\operatorname{Re}_{b}^{-2}+0.07089 G_{s}^{2}\right)^{1 / 4} .
$$


The liquid velocity profile near the wall is estimated by using universal single-phase turbulent flow profile:

$$
v^{+}=\frac{1}{k^{+}} \ln x^{+}+C^{+},
$$

where $k^{+}$and $C^{+}$are the constants depending on $x^{+}$, and

$$
\begin{aligned}
& v^{+} \equiv \frac{v_{f}}{v^{*}}=\frac{v_{f}}{\sqrt{\tau_{w} / \rho_{f}}}, \\
& x^{+} \equiv \frac{x v^{*}}{v_{f}}=\frac{x \sqrt{\tau_{w} / \rho_{f}}}{v_{f}} .
\end{aligned}
$$

The universal dimensionless velocities for different regions are

$$
\begin{cases}v^{+}=x^{+} & x^{+} \leq 5 \\ v^{+}=5 \ln x^{+}-3.05 & 5<x^{+}<30 . \\ v^{+}=2.5 \ln x^{+}+5.5 & x^{+} \geq 30\end{cases}
$$

In order to keep the $\ln x^{+}$as shown in Equation (17) for later derivation, the first equation in Equation (20) is changed to

$$
v^{+}=\frac{4}{\ln 5} \ln x^{+}+1 \quad x^{+}<5 .
$$

The new equation equals to the equation $u^{+}=x^{+}$when $x^{+}$is 1 or 5 , and the difference in the range of $1<x^{+}<5$ is smaller than $14 \%$. This approximation would not bring much error because the bubble radii are in the range of $x^{+}>1$ in the present experiment results.

The wall shear stress $\tau_{w}$ can be calculated by

$$
\tau_{w}=C_{f} \cdot \frac{1}{2} \rho_{f} \bar{v}_{f}^{2}
$$

where $\bar{v}_{f}$ is the area-averaged liquid velocity, and $C_{f}$ is the friction coefficient as

$$
C_{f}=\frac{\lambda}{4}
$$

where $\lambda$, the friction factor for a smooth surface, is expressed by

$$
\begin{cases}\lambda=\frac{64}{\operatorname{Re}} & \operatorname{Re}<2320 \\ \lambda=\frac{0.3164}{\operatorname{Re}^{0.25}} & 4 \times 10^{3}<\operatorname{Re}<10^{5} \\ \lambda=0.0032+0.221 \operatorname{Re}^{-0.237} & 10^{5}<\operatorname{Re}<3 \times 10^{6}\end{cases}
$$

where the single phase liquid Reynolds number, is used.

When a bubble is lift-off, the bubble may slide on the heating surface. However, literature review finds no model or empirical correlation on bubble sliding velocity. In the present study, a relative velocity coefficient is introduced as

$$
C_{r} \equiv v_{r} / v_{f}
$$

where $v_{f}$ is the local liquid velocity at the bubble centre of mass. $C_{r}$ is unity when the bubble is not sliding, and it is zero when the bubble velocity is the same as the liquid velocity. Thus, the relative velocity coefficient is between 0 and 1 during the bubble lift-off process.

By implementing Equation (17), one can derive the shear rate term in Equation (14) as 


$$
\frac{d v}{d x}=\frac{v^{* 2}}{\bar{v}_{f}} \frac{d v^{+}}{d x^{+}}=\frac{v^{* 2}}{\bar{v}_{f}} \frac{1}{k^{+} x^{+}}=\frac{v^{*}}{k^{+} x} .
$$

Thus Equation (14) becomes

$$
G_{s}=\left|\frac{d v}{d x}\right|_{x=r_{b}} \frac{r_{b}}{v_{r}}=\left|\frac{v^{*}}{k^{+} x}\right| \frac{r_{b}}{v_{r}}=\frac{1}{C_{r} k^{+} v^{+}} .
$$

\subsection{Development of Bubble Lift-Off Size Model}

Equation (1) can be re-written

$$
-\rho_{f} \pi r_{b}^{2}\left(\frac{11}{2} \dot{r}_{b}^{2}+\frac{11}{6} r_{b} \ddot{r}_{b}\right)+\frac{1}{2} C_{l} \rho_{f} \pi r_{b}^{2} v_{r}^{2}=0
$$

Furthermore, substituting Equation (7) into Equation (28) yields

$$
\frac{\alpha_{f}}{t_{l o}}=\frac{3 \pi C_{l} v_{r}^{2}}{22 b^{2} \mathrm{Ja}^{2}},
$$

where $t_{l o}$ is the time of lift-off. It can be derived from Equation (7) as

$$
t_{l o}=\frac{\pi r_{l o}^{2}}{4 b^{2} \mathrm{Ja}^{2} \alpha_{f}}
$$

By substituting Equation (30) into Equation (29), we can get

$$
C_{l}\left(\frac{v_{r} D_{l o}}{v_{f}}\right)^{2}=\frac{352 b^{4}}{3 \pi^{2}} \mathrm{Ja}^{4} \operatorname{Pr}_{f}^{-2}
$$

where $\operatorname{Pr}_{f}$ is the liquid Prandtl number, $\operatorname{Pr}_{f}=v_{f} \alpha_{f}$. A new dimensionless parameter of the bubble lift-off diameter is now defined by

$$
D_{l o}^{*} \equiv \sqrt{C_{l}} \operatorname{Re}_{b}=\sqrt{C_{l}}\left(\frac{v_{r} D_{l o}}{v_{f}}\right) .
$$

The dimensionless bubble lift-off diameter is now a function of the Jacob number and the Prandtl number as

$$
D_{l o}^{*}=\frac{4 \sqrt{22 / 3} b^{2}}{\pi} \mathrm{Ja}^{2} \operatorname{Pr}_{f}^{-1} .
$$

In forced-convective subcooled boiling flow, the effective wall superheat should be used for the Jacob number as discussed earlier. This yields

$$
D_{l o}^{*}=\frac{4 \sqrt{22 / 3} b^{2}}{\pi} \mathrm{Ja}_{e}^{2} \operatorname{Pr}_{f}^{-1}
$$

\section{Experiments}

\subsection{Experimental facility, setup and conditions}

An experimental facility has been designed to measure the relevant two-phase parameters necessary for developing constitutive models for the two-fluid model in subcooled boiling flow. The experimental facility is a scaled-down loop from a prototypic BWR based on proper scaling criteria for geometric, hydrodynamic, and thermal similarities (Bartel et al. 2001; Situ et al. 2004a). The details of test facility, setup, and conditions are described in the previous papers (Situ et al. 2004b, 2006). Typical consecutive images of bubble departure, sliding, and lift-off are shown in Figure 2. In this test condition, the heat flux, $q^{\prime \prime}$, is $145 \mathrm{~kW} / \mathrm{m}^{2}$, the inlet liquid velocity, $v_{\text {fin }}$, is $0.927 \mathrm{~m} / \mathrm{s}$, the inlet temperature, $T_{i n}$, is $90^{\circ} \mathrm{C}$, and the heating length from the start of the heated section to the 


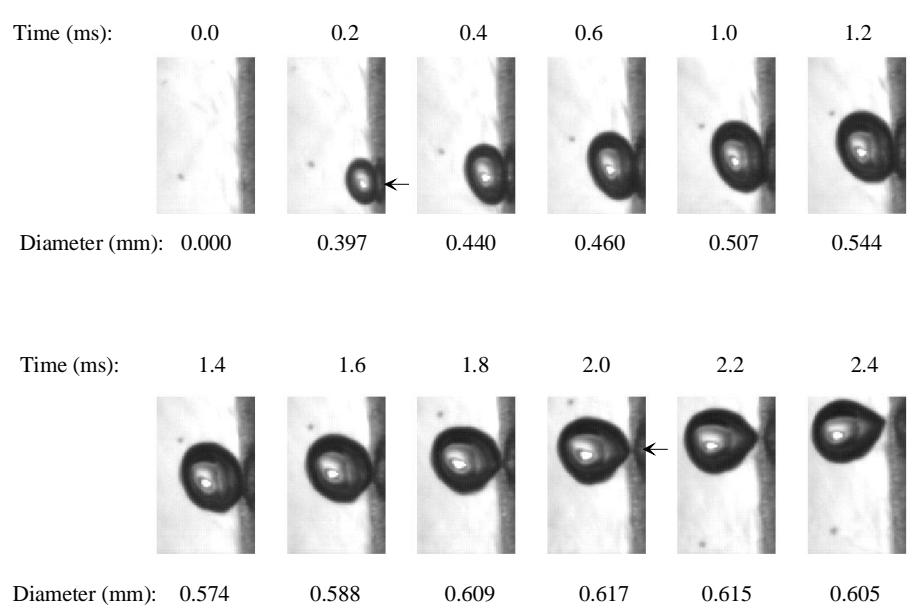

Figure 2. Typical consecutive images of bubble departure and lift-off.

nucleation site, $z_{d}$, is $1.12 \mathrm{~mm}$. The arrow at the time of $0.2 \mathrm{~ms}$ is the location of nucleation site, while the arrow at $2.0 \mathrm{~ms}$ is the location of bubble lift-off.

\subsection{Experimental results and discussion}

The measured bubble lift-off diameters are shown against the inlet temperature in Figure 3. It is suggests that the bubble lift-off diameter increases as the increase of inlet temperature. Because nucleation sites are located at different axial positions on an industrial-manufactured heat rod, the cavity is naturally distributed with unknown cavity size. It is rather difficult to compare the bubble lift-off diameters among different nucleation sites. Figure 4 shows the bubble lift-off diameter against the inlet temperature for one nucleation site at $z_{d}=1.13 \mathrm{~m}$. The $\mathrm{O}$ data $\left(q^{\prime \prime}=202 \mathrm{~kW} / \mathrm{m}^{2}\right)$ is linearly fitted by the solid curve, and the $\Delta$ data (with $q^{\prime \prime}=146 \mathrm{~kW} / \mathrm{m}^{2}$ ) is fitted by the broken curve.It clearly shows that the increase of inlet temperature causes the increase of bubble lift-off diameter. In addition, the effect of fluid velocity is suggested by comparing the $\square$ and $\nabla$ data. Assuming the dependence of the $\square$ and $\nabla$ data on the inlet temperature are similar to the solid and broken curves in the figure, the curve with lower fluid velocity $\left(\nabla, v_{f i n}=0.487 \mathrm{~m} / \mathrm{s}\right)$ would be higher than that with higher inlet fluid velocity $\left(\square, v_{\text {fin }}=0.912 \mathrm{~m} / \mathrm{s}\right)$. Furthermore, the effect of the heat flux can be found in this figure. The data indicated by $\mathrm{O}, \Delta$, and $\square$ have similar inlet fluid velocity but different heat flux. The figure suggests that the solid curve is higher than the broken curve, and the broken curve is higher than the $\square$ data (with $q^{\prime \prime}=101 \mathrm{~kW} / \mathrm{m}^{2}$ ). In summarization, higher inlet temperature, lower fluid velocity, or higher heat flux would give rise to higher wall temperature at the nucleation site, and hence cause higher bubble lift-off diameter.

Experimental observation finds that the results of bubble lift-off frequencies are almost equal to the bubble departure frequencies, which are reported in the previous paper (Situ et al. 2006). Thus it will not be detailed here. The difference between bubble departure frequency and lift-off frequency is the bubble collapse rate during bubble sliding before lift-off. In the present experimental conditions, bubbles seldom condense when they are sliding. However, in some higher temperature turbulence conditions, bubble might meet with cold liquid, and condense quickly. Investigation of bubble sliding is strongly recommended in future study. 

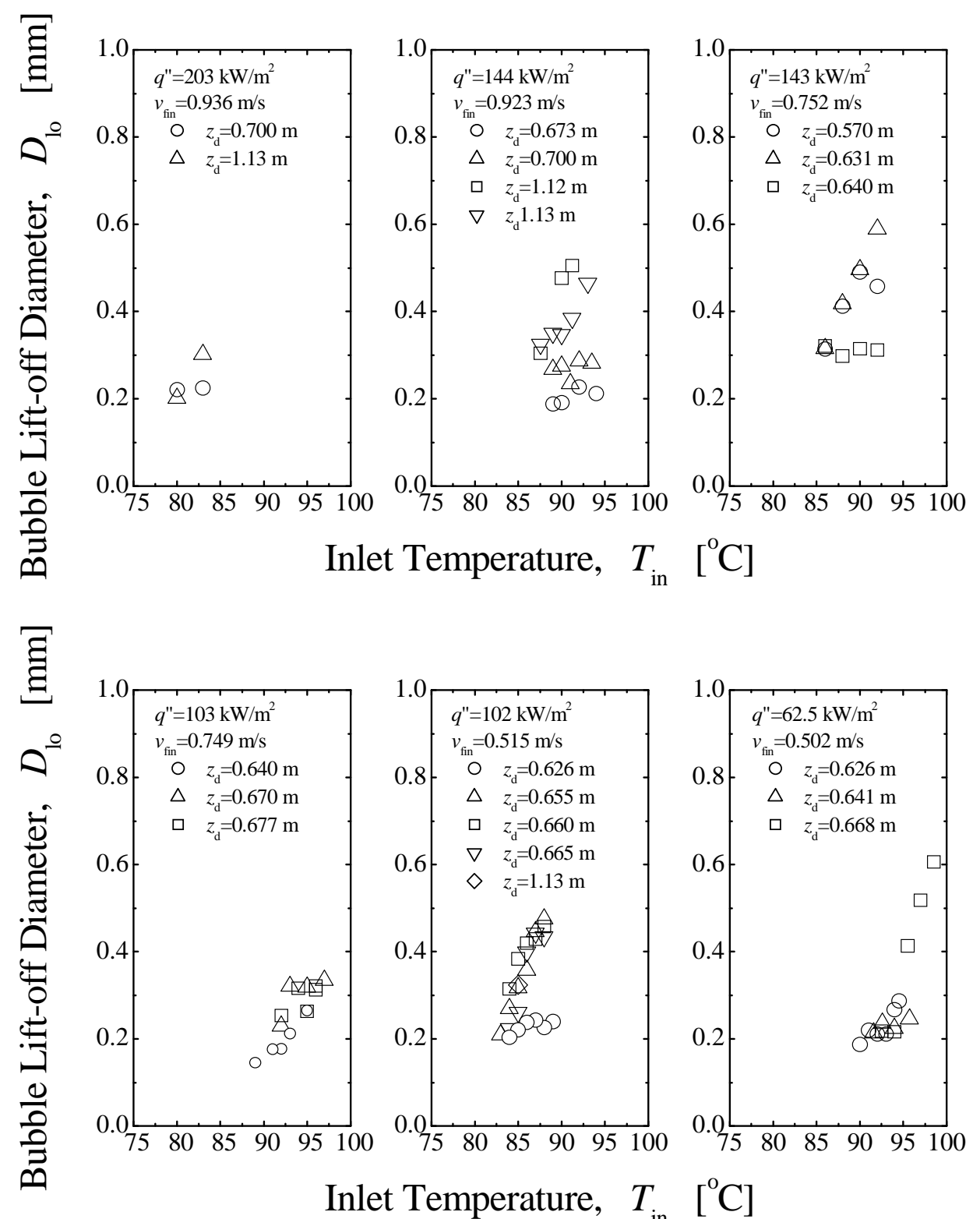

Figure 3. Dependence of bubble lift-off diameter on inlet temperature.

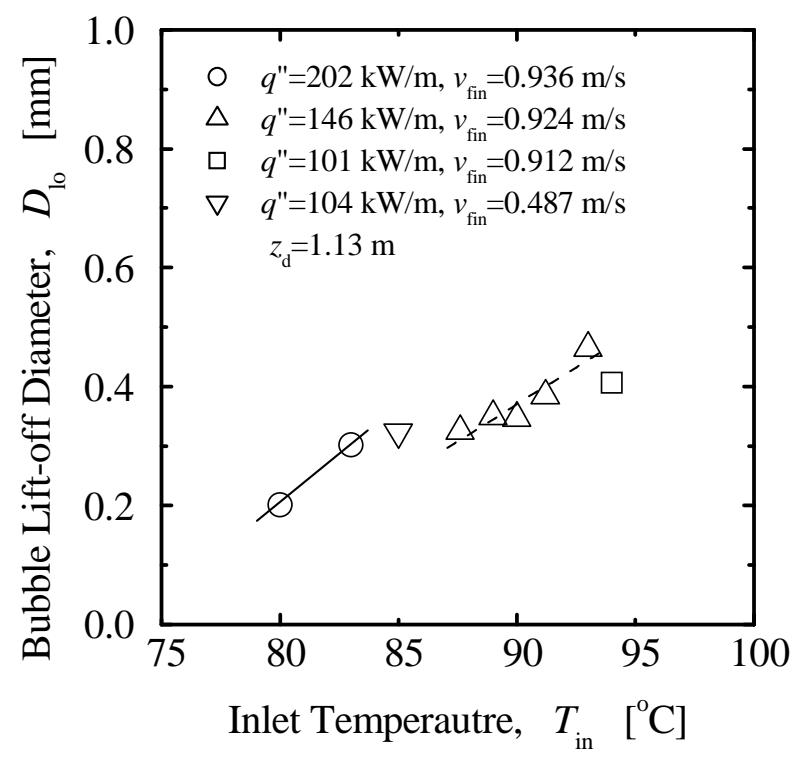

Figure 4. Dependence of bubble lift-off diameter on inlet temperature at $Z_{d}=1.13 \mathrm{~m}$. 


\subsection{Comparison of lift-off model with experimental data}

The wall temperature at the nucleation site is the must-know parameter in calculating the effective $\mathrm{Jacob}$ number, $\mathrm{Ja}_{e}$. Since wall temperature is not directly measured in the current study, the wall temperature is calculated by using existing correlations or models.

In the present study, Sato and Matsumura's correlation (1964) (cited by Davis and Anderson (1966)) is used to calculate the Onset of Nucleation Boiling (ONB)

$$
q_{\text {ONB }}^{\prime \prime}=\frac{k_{f} i_{f g} \rho_{v}}{8 \sigma T_{\text {sat }}}\left(T_{w}-T_{\text {sat }}\right)^{2},
$$

Chen's correlation (1966) is used to calculate the wall temperature in the subcooled boiling regions (modified by Collier 1982)

$$
q^{\prime \prime}=h_{N B}\left(T_{w}-T_{s a t}\right)+h_{c}\left(T_{w}-T_{b u l k}\right),
$$

where

$$
h_{c}=0.023 \operatorname{Re}_{f}^{0.8} \operatorname{Pr}_{f}^{0.4} \frac{k_{f}}{D_{H}} F,
$$

where the factor $F$ is set to unity and

$$
h_{N B}=0.00122\left(\frac{k_{f}^{0.79} C_{p f}^{0.45} \rho_{f}^{0.49}}{\sigma^{0.5} \mu_{f}^{0.29} i_{f g}^{0.24} \rho_{g}^{0.24}}\right) \Delta T_{\text {sat }}^{0.24} \Delta \rho^{0.75} S,
$$

Due to the short test section length and relatively small heater power available, the estimation of the point of net vapor generation does not considerably affect the calculation of the wall temperature.

The effect of relative velocity coefficient is shown in Figure 5. The averaged prediction error, $E$, is defined as

$$
E \equiv \frac{\left|D_{l o, e x p}^{*}-D_{l o, p r e d}^{*}\right|}{D_{l o, e x p}^{*}} \times 100 .
$$

The figure suggests that the averaged prediction errors of the dimensionless bubble lift-off diameter are nearly constant below $40 \%$ when $C_{r}$ is between 0.4 and 1 . Since there is no model of the bubble sliding velocity available, the bubble sliding velocity is assumed to be half of the local liquid

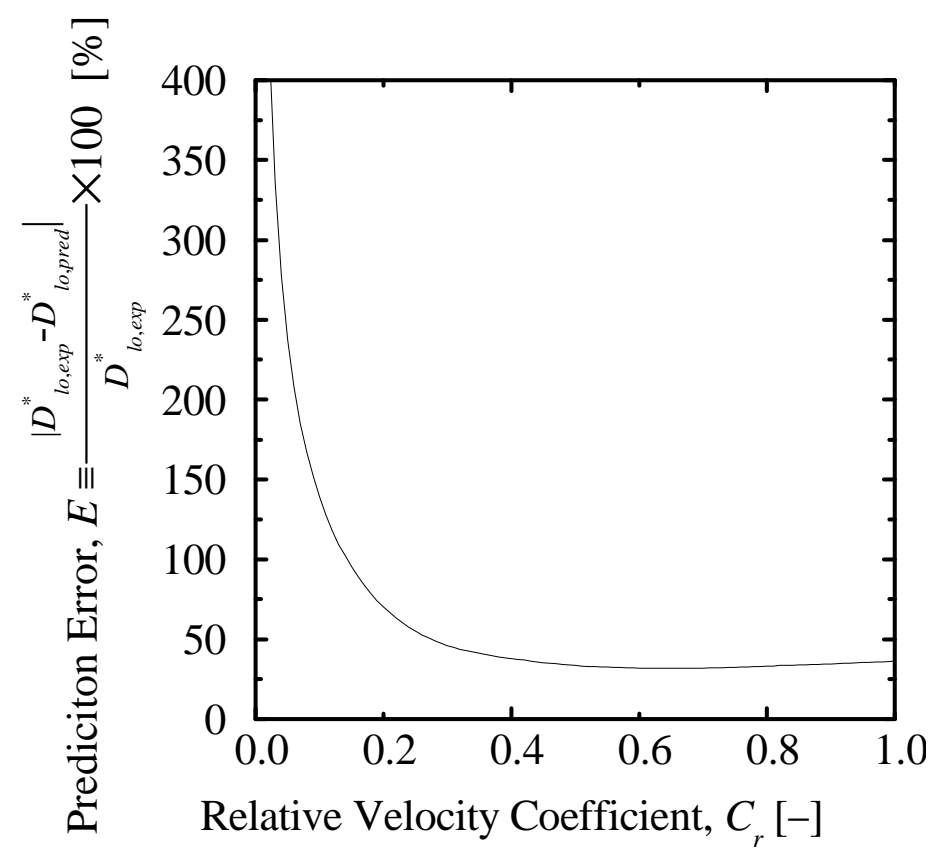

Figure 5. Dependence of prediction error on relative velocity coefficient. 


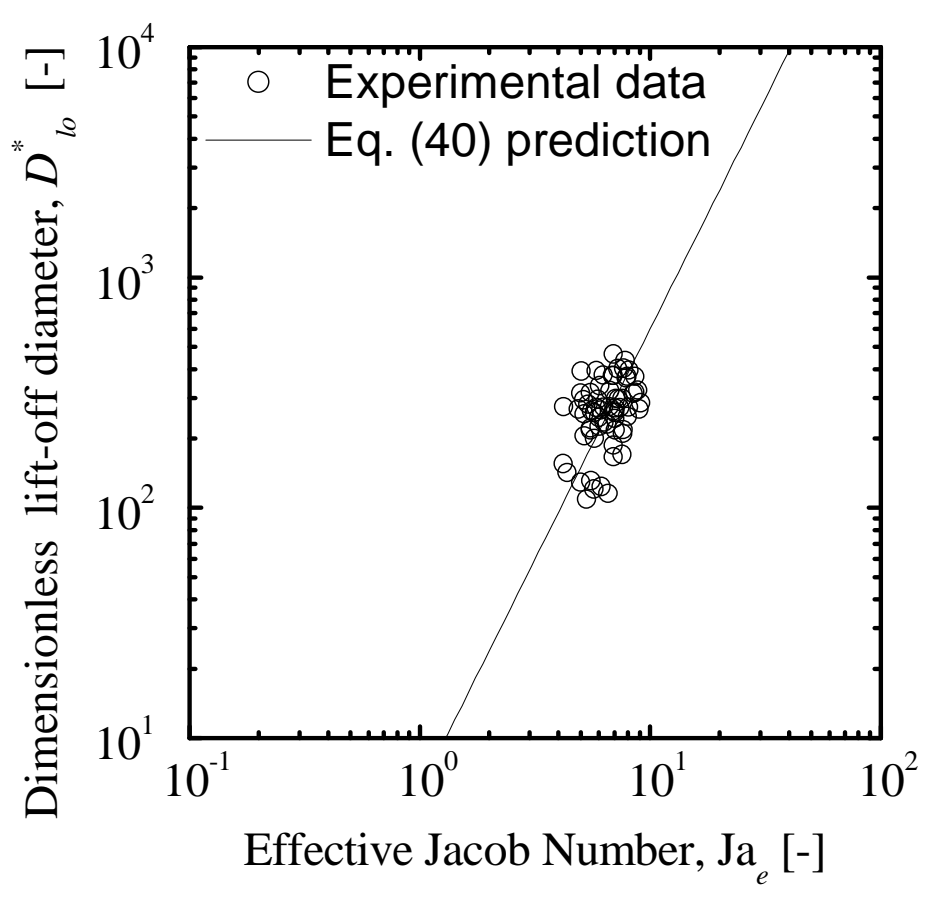

Figure 6. Comparison between predicted and measured bubble lift-off diameters.

velocity, i.e. $C_{r}=0.50$. The model prediction and experimental data are presented in the $\mathrm{Ja}_{e}-D_{l o}^{*}$ figure, as shown in Figure 6. The figure suggests that data falls on the model-predicted line. The average prediction error is $\pm 33.6 \%$.

No other bubble lift-off diameter data in upward flow is founded in literature. For horizontal flow, the buoyancy force should be considered in analysing force balance. Zeng et al. (1993) have 38 data sets of R113 in horizontal flow. Using the expression of pressure and gravity force, the bubble liftoff diameter can be calculated. The comparison between calculated bubble lift-off diameter and experimental data shows the average prediction error is $\pm 48.8 \%$. This suggests that the expressions of growth force and shear lift force are reasonable.

In a future study, extensive data of bubble lift-off diameter on various working fluids and various test conditions should be taken to evaluate the model. It is also suggested that further investigation of the sliding velocity may be conducted on both experimental and theoretical aspects: At experimental aspect, the bubble sliding velocity can be measured by analysing the consecutive bubble sliding images. While at the theoretical aspect, the bubble sliding velocity might be obtained by assuming force balance along the flow direction. Recently, Sateesh et al. (2005) calculated the sliding velocity along horizontal tube surface. It might be a promising approach.

\section{Conclusions}

Bubble lift-off is different from bubble departure, and it is more suitable for the boundary condition for numerical simulation of subcooled boiling flow. The forces acting on a growing bubble at the moment of lift-off were discussed. Force balance analysis showed that the bubble is governed by growth force and shear lift force at the instant of the lift-off. A dimensionless term of bubble lift-off diameter was found to be a function of Jacob number and Prandtl number. The modeling of bubble lift-off frequency requires careful study of bubble collapse during sliding.

Forced convective subcooled flow boiling experiments were conducted in a BWR-scaled vertical- 
upward annular channel by using water as testing fluid. The test runs were performed at atmosphere pressure. The inlet temperature ranged from 80.0 to $98.5^{\circ} \mathrm{C}$; the inlet velocity varied from 0.487 to $0.939 \mathrm{~m} / \mathrm{s}$; and the heat flux changed from 60.7 to $206 \mathrm{~kW} / \mathrm{m}^{2}$. A high-speed digital video camera was used to capture the dynamics of the subcooled nucleation process. Bubble lift-off diameters and lift-off frequencies were obtained from the images for a total of 92 test conditions. The results indicated that bubble lift-off diameter increases with increasing of the inlet temperature, increasing of the heat flux, or decreasing of the inlet fluid velocity. The bubble lift-off frequency is almost equal to the bubble departure frequency.

The comparison between the proposed model and experimental data finds that the averaged prediction errors of the dimensionless bubble lift-off diameter are almost constant when the bubble sliding velocity is less than $60 \%$ of the local liquid velocity. For simplicity, the sliding velocity is set as half of the local liquid velocity, and it gives a reasonable prediction within the averaged relative deviation of $\pm 35.2 \%$.

\section{Acknowledgements}

This research project is supported by Australian Research Council (ARC) Discovery Program. In addition, some part of the work was support by the Tokyo Electric Power Company (TEPCO). The authors would like to express their sincere appreciation for the support from ARC and TEPCO.

\section{References}

T. R. Auton, The lift force on a spherical body in a rotational flow, Journal of fluid Mechanics 183 (1987) 199-218.

M. Bartel, M. Ishii, T. Masukawa, Y. Mi, R. Situ, Interfacial area measurements in subcooled flow boiling, Nuclear Engineering and Design 210 (2001) 135-155.

J. C. Chen, Correlation for boiling heat transfer to saturated fluids in convective flow, I\&EC Process Design and Development 5 (1966) 322-329.

Y. Chen, M. Groll, R. Mertz, and R. Kulenovic, Force analysis for isolated bubbles growing from smooth and evaporator tubes, Transaction of the Institute of Fluid-Flow Machinery 112 (2003) $57-74$.

J. G. Collier, Heat transfer in the post dryout region and during quenching and reflooding, in G. Hetsroni (ed.), Handbook of Multiphase Systems, New York: Hemisphere, 1982.

E. J. Davis, and G. H. Anderson, The incipience of nucleate boiling in forced convection flow, AIChE Journal 12(1966) 774-780.

M. Ishii, Thermo-fluid dynamics theory and two-phase flow, Eyerolles, Paris, 1975.

J. F. Klausner, R. Mei, D. M. Bernhard, and L. Z. Zeng, Vapour bubble departure in forced convection boiling, International Journal of Heat and Mass Transfer 36 (1993) 651-662.

G. Kocamustafaogullari, and M. Ishii, Interfacial area and nucleation site density in boiling systems, International Journal of Heat and Mass Transfer 26 (1983) 1377-1387.

G. Kocamustafaogullari, and M. Ishii, Foundation of the interfacial area transport equation and its closure relations, International Journal of Heat and Mass Transfer 38 (1995) 481-493.

D. Legendre, J. Magnaudet, A note on the lift force on a spherical bubble or drop in a lowReynolds-number shear flow, Physics of Fluid 9 (1997) 3572-3574.

S. Levy, Forced convection subcooled boiling-prediction of vapour volumetric fraction, International Journal of Heat and Mass Transfer 10 (1967) 951-965.

J. B. McLaughlin, Inertial migration of a small sphere in linear shear flows, Journal of Fluid Mechanics 224 (1991) 261-274.

R. Mei, and J. F. Klausner, Shear lift force on spherical bubbles, International Journal of Heat and Fluid Flow, 15 (1994) 62-65. 
R. M. Podowski, D. A. Drew, R. T. Lahey, Jr., and M. Z. Podowski, A mechanistic model of the ebullition cycle in forced convection subcooled boiling, Proceedings of Eight International Topical Meeting on Nuclear Reactor Thermal-Hydraulics, 3 (1997) 1535- 1542.

P. G. Saffman, The lift on a small sphere in a slow shear flow, Journal of Fluid Mechanics 22 (1965) 385-400.

G. Sateesh, S. K. DAs, Ar. R. Balakrishnan, Analysis of pool boiling heat transfer: effect of bubbles sliding on the heating surface, International Journal of Heat and Mass Transfer 48 (2005) 15431553.

R. Situ, T. Hibiki, X. Sun, Y. Mi, M. Ishii, flow structure of subcooled boiling flow in an internally heated annulus, International Journal of Heat and Mass Transfer 47 (2004a) 5351-5364.

R. Situ, Y. Mi, M. Ishii, and M. Mori, Photographic study of bubble behaviours in forced convection subcooled boiling, International Journal of Heat and Mass Transfer 47 (2004b) 36593667.

R. Situ, J. Y. Tu, G. H. Yeoh, G. C. Park, T. Hibiki, M. Ishii, Bubble departure in forced convective subcooled boiling flow, accepted by $14^{\text {th }}$ International Heat Transfer Conference (2006).

L. Z. Zeng, J. F. Klausner, D. M. Bernhard, and R. Mei, A unified model for the prediction of bubble detachment diameters in boiling systems - II. Flow boiling, International Journal of Heat and Mass Transfer 36 (1993) 2271-2279.

N. Zuber, Hydrodynamic aspects of boiling heat transfer, U.S. AEC Rep. AECU 4439, Tech. Inf. Serv. Oak Ridge, Tenn. (1959).

N. Zuber, The dynamics of vapour bubbles in nonuniform temperature fields, International Journal of Heat and Mass Transfer 2 (1961) 83-98.

N. Zuber, Recent trends in boiling heat transfer research Part I: Nucleate pool boiling, Applied Mechanics Reviews, 17 (1964) 663-672. 